\title{
Clinical issues of headaches: a personal view
}

\author{
Gennaro Bussone ${ }^{1}$
}

Published online: 8 March 2019

(C) Fondazione Società Italiana di Neurologia 2019

There is no doubt that headache is the main symptom that makes the vast majority of patients seek neurological advice. The truth is that, among all diseases, headache is one of the hardest to diagnose and treat. It is, in fact a functional CNS disorder and no specific markers or organic alterations occur, except when headache is a symptom of another illness.

Moreover, after trying several medical, paramedical, or allbut-medical approaches, most patients continue to suffer from their headache and, being often dissatisfied with the responses obtained, they try self-treatments and thus become pain-killer abusers. For patients it is therefore important to hear from a physician that their disorder has a name - migraine "with aura" or "without aura"; "tension type" headache; or "cluster headache." This, alone, may dispel the anxiety and uncertainty they have been suffering from, sometimes for years. Hence a direct positive impact on the quality of life that, being always low with this disorder, may even interfere with the recommended treatments. This is even more true if we consider that while headaches can, indeed, be described, their description is hardly objective, and they therefore fall within the domain of subjectivity.

The subjectivism of this pathology never fails to strike me. Patients describe their symptoms, but physicians can never verify them directly; therefore, a relation needs to be established between the physician and the patient, allowing both to work together to find a solution to the problem, and making it easier for the physician to listen to and interpret the language of symptoms, which may characterize the patient's condition but cannot be unveiled through an "objective" clinical examination.

Throughout my career as a headache neurologist, I have seen several scientific theories on the pathophysiology of headaches, from the peripheral vascular hypothesis to the in-

Gennaro Bussone

studiobussone@gmail.com

1 Founder The Center for Headaches and Primary Emeritus of the C. Besta Neurological Institute and IRCCS Foundation, Milan, Italy volvement of the central nervous system. However, because of the essential characteristic of subjectivity, no one has been able so far to pin down the causes for primary headaches: the hoped-for primum movens is still to be found and it becomes increasingly clear that a headache condition may have multiple contributing causes.

It seems to me that the hypothesis of a dysfunctional interaction between nervous system areas concerned with the emotion and pain pathways is a very promising one [1]. Such dysfunction appears to affect homeostasis, as argued by Bud Craig and Antonio Damasio, which means that altered biobehavioral responses to head pain give rise to various clinical phenomena manifesting in headaches [2, 3, 4].

In the near future, neurochemical and functional imaging studies are likely to provide further insights into the pathophysiology of primary headaches, particularly those investigating relationships between emotion and pain. In this context, pain is merely part of a patient's behavioral response. It is now clear, in fact, that in many patients, simply concentrating on pain alone often leads to treatment failure if this is not integrated with a bio-psychological approach. It therefore seems to me that the historical interpretation of headaches demonstrates the need to use critical intelligence to advance knowledge. I believe this analysis should suggest that, when dealing with headaches, subjectivism itself should be enhanced, in that it is what makes the study of headaches so intriguing.

Empathy with sufferers can help us focus on aspects that, while apparently negligible, sometimes allow perceiving an element that is peculiar to a still unclear clinical condition. One example is the lesson provided by Kunkle in 1952, highlighting the time parameter, until then neglected, to suggest the clinical uniqueness of cluster headaches, earlier described with a variety of names.

It is therefore useful to associate organ-specific medicine with some elements of holistic medicine, considering man as a whole. In time, in fact, research separated the body from the mind and, for the future, we need to reinstate Plato's old-time idea of "healing the soul to heal the body." 
I would also argue that the historical interpretation of headaches demonstrates the need to use critical, unbiased intelligence released from tradition, in order to advance the knowledge of this typically subjective disease. We need the courage to interpret facts by setting aside what we know, because traditional positions or temporary fashionable explanations often conceal true facts.

The above highlights the utmost importance of clinical research to interpret and treat headaches. Clinical research calls for organization, time, passion, expertise, motivationmandatory requirements for anyone wishing to transfer intuitions or ideas into the study of headaches in order to improve the quality of life and the disability of sufferers.

This introduces another consideration: when an individual falls ill with a disease affecting an organ, such disease can surely be treated, but is then perceived and processed by the brain and through the personal way of thinking. This process can continue for months, sometimes for years. Therefore, the disease should not be treated at physical level only, but also at mental level. This means that physicians need to establish a new, closer, more interactive relation with patients to stimulate their trust. We need to be able to listen!

Listening is crucial for a physician, and is first and foremost a display of love towards the patient. Our common goal is to improve the life of these patients.

\section{Compliance with ethical standards}

Conflict of interest The author declares that he has no conflict of interest.

Ethical standards This article does not contain any study with human subjects performed by the author.

Publisher's note Springer Nature remains neutral with regard to jurisdictional claims in published maps and institutional affiliations.

\section{References}

1. Bussone G, Grazzi L, Panerai AE (2012) Pain, emotion, headache. Headache 52(Suppl 2):98-101. https://doi.org/10.1111/j.1526-4610. 2012.02244.x

2. Craig AD (2006) A new view of pain as a homeostatic emotion. Trends Neurosci 26:303-307

3. Craig AD (2009) How do you feel-now? The anterior insula and human awareness. Nat Rev Neurosci 10(1):59-70. https://doi.org/10. 1038/nrn2555

4. Damasio A (2003) Feeling and emotion and self. Ann N Y Acad Sci 1001:253-261 